\title{
Cultivos de outono-inverno na supressão de plantas daninhas em soja
}

\author{
Germani Concenço1, Gessi Ceccon¹, Rodolpho Freire Marques², Ilce Rojas Marschall ${ }^{3}$ \\ Maxwell Eliézer dos Santos Alves ${ }^{3}$, Waggner Gomes Palharini ${ }^{4}$, Leandro Galon ${ }^{5}$
}

\footnotetext{
${ }^{1}$ Embrapa Agropecuária Oeste, BR 163, km 253,6, Zona Rural, CEP 79804-970, Dourados-MS, Brasil. Caixa Postal 449. E-mail: germani.concenco@embrapa.br; gessi.ceccon@embrapa.br

2 Universidade Federal da Grande Dourados, Faculdade de Ciências Agrárias, Programa de Pós-Graduação em Agronomia, Rodovia Dourados-Itaum, km 12, CEP 79804-970, Dourados-MS, Brasil. Caixa Postal 533. E-mail: rodphfm@hotmail.com

${ }^{3}$ Centro Universitário da Grande Dourados, Rua Iguassu, até 849/850, Vila Aurora, CEP 79823-150, Dourados-MS, Brasil. E-mail: ilce_rmarschall@hotmail.com maxwell-27@hotmail.com

${ }^{4}$ Universidade Federal de Viçosa, Programa de Pós-Graduação em Fitotecnia, Av. P.H. Rolfs, s/n, Centro, CEP 36571-000, Viçosa-MG, Brasil. E-mail: palharini@agronomo.eng.br

${ }^{5}$ Universidade Federal da Fronteira Sul, Campus Erechim, Rodovia ERS 135, km 72, Interior de Erechim, CEP 99700-000, Erechim-RS, Brasil. E-mail: leandro.galon@uffs.edu.br
}

\section{RESUMO}

Vários fatores reduzem a produtividade das culturas, como a incidência de plantas daninhas cuja supressão pode ser alcançada com rotação de culturas. Objetivou-se analisar a composição da comunidade infestante na soja após um e três anos de distintas sucessões de cultivo. A soja foi cultivada anualmente (outubro a fevereiro) sobre os seguintes tratamentos de outono-inverno: Milho $90 \mathrm{~cm}$ entrelinhas; Milho $45 \mathrm{~cm}$ entrelinhas; Milho $90 \mathrm{~cm}$ com B. ruziziensis; B. ruziziensis; Feijão-caupi. As avaliações foram realizadas 15 dias após a emergência da soja. Após três anos, os tratamentos apresentaram aumento de infestação em relação ao primeiro ano, onde a planta daninha mais importante foi $B$. pilosa, que após três anos foi parcialmente substituída por L. nepetifolia e E. heterophylla. Maiores coeficientes de diversidade estiveram associados a maiores níveis de infestação, pois as novas espécies observadas se somaram às presentes. $A$. hybridus foi a espécie mais persistente, presente em ambos os anos de estudo. A braquiária contribuiu para menor infestação, e os cultivos de milho a $90 \mathrm{~cm}$ e feijão caupi proporcionaram aumento no nível de infestação.

Palavras-chave: Consórcio, infestação, manejo, sucessão de cultivos

\section{Weed suppression with brachiaria in soybean crop}

\begin{abstract}
Several factors reduce crop yield, including weed occurrence, which can be suppressed by crop rotation. We aimed with this study to analyze the composition of the weedy community after one and three years of distinct crop successions. Soybean was annually planted between October and February in areas previously cropped with one of the following treatments: maize planted in rows spaced in 45 or $90 \mathrm{~cm}$; intercropping maize + Brachiaria ruziziensis; B. ruziziensis alone; and cowpea. Evaluations were carried out 15 days after soybean emergence. After three years, treatments tended to be more infested compared to the first year; the most important weed species was B. pilosa, which after three years was partially substituted by L. nepetifolia and E. heterophylla. Higher diversity coefficients were associated to higher infestation levels because new weed species joined while older species were not completely suppressed. A. hybridus was the most persistent one, being present in both years. Brachiaria planted in the second crop highly contributed for lower weed occurrence in the following soybean crop, and corn planted in rows spaced in 90 $\mathrm{cm}$ and cowpea promoted increased weed occurrence.
\end{abstract}

Key words: Intercrop, infestation, management, succession planting 


\section{Introdução}

Com o crescimento populacional e a crescente demanda por alimentos, há necessidade de estudos que objetivam maximizar a produção das culturas com uso de métodos sustentáveis de cultivo. Vários fatores podem reduzir a produtividade das culturas, dentre eles a interferência de plantas daninhas. Estimase que em média cerca de $20-30 \%$ do custo de produção de uma lavoura se deve ao custo de controle das plantas daninhas (Silva, 2009); devido a isto, métodos complementares ao controle químico vêm sendo utilizados, como a rotação de culturas que consiste em alternar, anualmente, espécies vegetais numa mesma área agrícola, e o consórcio de espécies como o milho + braquiária que proporciona melhor cobertura do solo até a safra de verão subsequente.

O milho de segunda safra muitas vezes é a melhor opção após a colheita da soja, mas geralmente alguns fatores impossibilitam a semeadura do milho antes da data limite de 10 de março (Lazzarotto, 2002), o que faz com que os produtores optem por deixar essas áreas em pousio. O milho de segunda safra é, em grande parte da área, semeado no sistema de consórcio com braquiária, o que garante melhor cobertura do solo após a colheita, servindo de barreira à proliferação de plantas daninhas na entressafra (Souza et al., 2006, Ceccon et al., 2013).

O consórcio milho + braquiária já provou sua eficiência na supressão de plantas daninhas (Ceccon et al., 2013), mas a sucessão soja/milho + braquiária não deve ser utilizada continuamente fora de um esquema de rotação ou de integração lavoura-pecuária. Em Mato Grosso do Sul, por exemplo, o nematoide Pratylenchus foi favorecido em áreas de sucessão soja/milho, devido não haver no sistema plantas que colaborem na inibição do seu desenvolvimento (Mainardi, 2013), mostrando a necessidade de rotacionar no sistema outras espécies.

A comunidade infestante de determinada lavoura não varia somente a composição florística, mas também a predominância de cada espécie (Austin \& Greig-Smith, 1968). Estudos fitossociológicos permitem avaliar a composição de espécies de um dado dossel vegetal e estimar a abundância (ou densidade), frequência e dominância (ou cobertura) de determinada comunidade vegetal. Com esses parâmetros sinecológicos também é possível estimar a importância relativa de cada espécie na área e, assim, prever danos às culturas que serão semeadas, provocados por cada fração da infestação (Gomes et al., 2010).

Além disso, é possível estudar cada área ou tratamento em função da variedade de espécies presentes ao utilizar índices de diversidade, bem como comparar tratamentos ou áreas entre si, pelo uso de índices sinecológicos de similaridade. Essa riqueza de informações acerca da comunidade vegetal em determinada área subsidia a compreender que tipos de interação estão ocorrendo e quais espécies estão sendo selecionadas pelo sistema de manejo e práticas adotados na área.

Embora a utilização de culturas sucessoras seja uma forma interessante de manejo de plantas daninhas, e os efeitos da sucessão sejam conhecidos, observa-se a escassez de trabalhos que demonstram o comportamento da comunidade infestante.
Estudos relacionados ao comportamento social de espécies vegetais infestantes são fundamentais para dar suporte a uma agricultura sustentável, sendo assim, o objetivo do trabalho foi analisar a composição da comunidade infestante após um e três anos de cultivos agrícolas distintos pós-soja, na ausência de rotação de culturas.

\section{Material e Métodos}

O ensaio foi conduzido na área experimental da Embrapa Agropecuária Oeste, situada na cidade de Dourados, Mato Grosso do Sul, Brasil, localizado nas coordenadas geográficas $22^{\circ} 16^{\prime} \mathrm{S}$ e $54^{\circ} 49^{\prime} \mathrm{W}$ e $408 \mathrm{~m}$ de altitude. O delineamento experimental utilizado foi em blocos casualizados com quatro repetições. A dimensão da parcela foi de $10 \mathrm{~m}$ x $25 \mathrm{~m}$.

Todos os tratamentos foram anualmente semeados durante o primeiro decêndio de março, sendo sempre precedidos do cultivo de soja Roundup Ready ${ }^{\circledR}$ entre outubro e fevereiro, semeada sobre resteva do cultivo anterior. Durante o cultivo de soja nenhum herbicida com efeito residual foi utilizado.

Foram avaliados cinco tratamentos de outono-inverno, implantados em 2010/11 (primeiro ano) e 2008/09, 2009/10 e 2010/11 (após três anos em): (T1-1 e T1-3) Milho solteiro semeado a $90 \mathrm{~cm}$ entrelinhas, com 45.000 plantas ha ${ }^{-1}$; (T21 e T2-3) Milho solteiro semeado a $45 \mathrm{~cm}$ entrelinhas, com 45.000 plantas $\mathrm{ha}^{-1}$; (T3-1 e T3-3) Milho a $90 \mathrm{~cm}$ com 45.000 plantas ha $\mathrm{a}^{-1} \mathrm{em}$ consórcio com Brachiaria ruziziensis, semeada nas entrelinhas do milho com população final de 200.000 plantas ha ${ }^{-1}$; (T4-1 e T4-3) B. ruziziensis solteira semeada em linhas espaçadas em $45 \mathrm{~cm}$, com população final de 400.000 plantas ha $^{-1}$; e (T5-1 e T5-3) feijão-caupi variedade BRS Guariba, semeado em linhas espaçadas em $45 \mathrm{~cm}$, resultando em 200.000 plantas $\mathrm{ha}^{-1}$. Os tratamentos terminados em "1", as avaliações foram realizadas na safra de soja subsequente, no mês de novembro, após um ano de distintos cultivos na safrinha, enquanto os tratamentos terminados em "3" constaram da avaliação dos mesmos tratamentos, em área adjacente, onde os mesmos tratamentos foram conduzidos por três anos, portanto na quarta safra de soja.

A semeadura da soja foi realizada no segundo decêndio de outubro de cada ano, sendo as áreas dessecadas com $1.440 \mathrm{~g}$ e. a. ha ${ }^{-1}$ de glyphosate em torno de 20 dias antes da semeadura da soja. Sendo que, quinze dias após a emergência da soja, no final do mês de novembro de 2011, foram realizadas as avaliações de levantamento fitossociológico de plantas daninhas em todas as parcelas.

Para a avaliação fitossociológica, utilizou-se um quadrado metálico com área de $0,25 \mathrm{~m}^{2}$ que foi lançado aleatoriamente 10 vezes em cada área. As espécies encontradas em cada amostra foram primeiramente identificadas, coletadas, e armazenadas em pacotes de papel por espécie. Posteriormente os mesmos foram colocados em estufas reguladas à temperatura de $60^{\circ} \mathrm{C}$, durante 5 dias para posterior determinação da massa seca total.

Os índices de densidade relativa (densidade da espécie * 100 / total absoluto de todas as espécies), frequência relativa (frequência da espécie nas amostras * 100 / total absoluto da frequência), e dominância relativa (massa seca da espécie * 100 / massa seca total das plantas da amostra), foram 
calculados, sendo utilizados ainda para a obtenção do Valor de Importância (densidade relativa/3 + frequência relativa/3 + dominância relativa/3) de cada espécie em cada área. As áreas foram intra-avaliadas quanto a diversidade de espécies utilizados os métodos de Simpson (D = 1- $\left(\sum n i^{*}(n i-1) / N^{*}(\mathrm{~N}-1)\right)$ e de Shannon-Weiner $\left(\mathrm{H}^{\top}=\Sigma \mathrm{pi}^{*} \operatorname{Ln}(\mathrm{pi})\right)$, sendo ni $=$ número de indivíduos da espécie " $\mathrm{i}$ ”; $\mathrm{N}$ = número total de indivíduos na amostra; pi = proporção dos indivíduos na amostra que pertencem à espécie "i".

As áreas foram ainda comparadas entre si quanto a similaridade de espécies pelo coeficiente de Jaccard $(\mathrm{J}=\mathrm{c} /$ $(\mathrm{a}+\mathrm{b}-\mathrm{c}))$, onde $\mathrm{a}=$ número de espécies de plantas na área "a"; $\mathrm{b}=$ número de espécies na área "b"; $\mathrm{c}=$ número de espécies em comum nas áreas "a" e "b".

A matriz de dissimilaridade foi obtida pelo inverso dos coeficientes de Jaccard (1-J), sendo as áreas agrupadas por análise multivariada pelo método UPGMA (Sneath \& Sokal, 1973). A validação dos agrupamentos foi verificada pelo coeficiente de correlação cofenética, obtido pela correlação linear de Pearson entre a matriz original de similaridade e a matriz cofenética. Todos os índices e coeficientes foram obtidos no ambiente estatístico R (R Core Team 2013), utilizando os pacotes adicionais Hmisc, Vegan e ExpDes.

\section{Resultados e Discussão}

$\mathrm{Na}$ área sob primeiro cultivo (Figura 1), os tratamentos foram similares quanto ao número de plantas daninhas observadas nas parcelas, com aproximadamente 10 exemplares de espécies daninhas por metro quadrado de solo; o consórcio milho + braquiária, no entanto, resultou em mínima ocorrência de plantas daninhas no primeiro ano de cultivo na área, com uma planta daninha por metro quadrado (Figura 1). Quando estes resultados foram comparados aos obtidos com os mesmos cultivos com três anos consecutivos de implantação, observase que somente o consórcio milho + braquiária e a braquiária solteira foram capazes de manter os níveis de infestação baixos.

Mesmo a braquiária, utilizada isoladamente, não foi capaz de neutralizar o aumento da ocorrência de plantas daninhas na ausência de rotação de culturas, uma vez que a infestação foi maior em áreas com braquiária após três anos de cultivo, comparado a área com somente um ano de cultivo

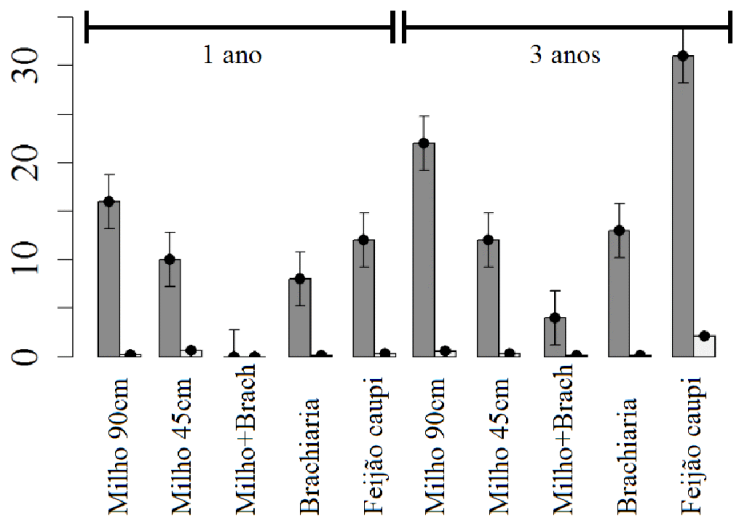

Figura 1. Número ( - $\left.\mathrm{m}^{-2}\right)$ e massa seca $\left(-\mathrm{g} \mathrm{m}^{-2}\right)$ de plantas daninhas, em função de períodos de utilização de distintos cultivos de inverno. Embrapa Agropecuária Oeste, Dourados-MS, 2012
(Figura 1). Após três anos de cultivo na ausência de rotação de culturas, os tratamentos com milho solteiro a $90 \mathrm{~cm}$ entrelinhas e feijão-caupi, resultaram em níveis de infestação 43,7 e $138,5 \%$ superiores aos respectivos tratamentos no primeiro ano de cultivo. Como a avaliação foi efetuada em estádios iniciais de desenvolvimento das plantas daninhas, a massa seca das infestantes não apresentou diferenças entre tratamentos (Figura 1).

O nível de infestação inicial de plantas daninhas em uma lavoura, na ausência de aplicação prévia de herbicidas residuais, expressa de maneira direta a riqueza do banco de sementes na área (Aldrich, 1984). A eficiência do herbicida depende da infestação inicial da área, ou seja, quanto maior a infestação, menor tende a ser a eficiência de controle devido ao sombreamento mútuo e a consequente menor cobertura da planta pelo herbicida (Silva et al., 2007); esta implicação faz com que área mal manejadas apresentem dificuldade cada vez maior para o controle das plantas daninhas, enquanto em áreas bem manejadas, com menor infestação natural, a aplicação de um herbicida adequado para controle das espécies daninhas tenha efeito eficaz com o manejo previamente aplicado, resultando em menores níveis de infestação absoluta.

Nas análises fitossociológicas (Tabela 1) são apresentadas somente as quatro principais plantas daninhas em cada área, sendo as demais, quando ocorreram, agrupadas como "Outras espécies". Como regra geral, a plantas daninha mais importante no primeiro ano, normalmente não foi a mais importante no mesmo tratamento após três anos de cultivo da mesma sucessão (Tabela 1). Assim, por exemplo, milho solteiro semeado a 90 cm entre linhas, por três anos, ocasiona redução na ocorrência de Bidens pilosa, mas acaba favorecendo o Leonotis nepetifolia (Tabela 1). Similarmente, a braquiária, tanto solteira como consorciada e milho a $45 \mathrm{~cm}$ entre linhas, promoveu redução na ocorrência de $B$. pilosa. Uma das espécies daninhas mais persistentes foi Amaranthus hybridus, que esteve presente após um e três anos de cultivo em todas as áreas, exceto no milho solteiro a $45 \mathrm{~cm}$ entre linhas, entre as mais importantes, independentemente do manejo de inverno (Tabela 1).

$\mathrm{Na}$ área de primeiro ano (somente um ciclo soja - cultivo de inverno), como espécie daninha de maior proliferação (com maior densidade), destacou-se B. pilosa, representando 80, 93 e $87,5 \%$ do total de espécies de plantas daninhas nas áreas de milho solteiro a $90 \mathrm{~cm}$ entre linhas, consórcio milho + braquiária e braquiária solteira, respectivamente; $A$. hybridus foi a espécie com maior densidade na área de feijão-caupi, com $83 \%$ do número de indivíduos (Tabela 1). Nas áreas de três anos de sucessão (início do quarto ciclo da soja), B. pilosa apresentou maior densidade somente na área de milho solteiro a $45 \mathrm{~cm}$ entre linhas, representando $45 \%$ dos indivíduos das espécies infestantes naquele tratamento (Tabela 1). A. hybridus, com importância secundária no primeiro ano na maioria das áreas, foi a espécie com maior número de indivíduos no consórcio, na braquiária solteira e no feijão-caupi, respectivamente com 75 , 92 e $23 \%$, no terceiro ano (Tabela 1 ).

A frequência, embora com difícil interpretação prática quando apresentada em termos percentuais, em termos absolutos descreve a proporção do total de pontos amostrados, que possui pelo menos um indivíduo da espécie em seu interior 
Tabela 1. Parâmetros fitossociológicos de ocorrência de plantas daninhas, em função de períodos de utilização de distintos cultivos de inverno. Embrapa Agropecuária Oeste, Dourados-MS, 2012

\begin{tabular}{|c|c|c|c|c|c|c|c|c|c|}
\hline \multirow{2}{*}{ Espécie } & DE & FR & DO & VI & \multirow{2}{*}{ Espécie } & DE & FR & DO & VI \\
\hline & \multicolumn{4}{|c|}{$(\%)$} & & \multicolumn{2}{|c|}{$(\%)$} & & \\
\hline \multicolumn{5}{|c|}{ Milho $90 \mathrm{~cm}-1$ ano } & \multicolumn{5}{|c|}{ Milho $90 \mathrm{~cm}-3$ anos } \\
\hline B. pilosa & 80,0 & 33,3 & 15,8 & 43,1 & L. nepetifolia & 50,0 & 50,0 & 16,67 & 38,9 \\
\hline I. purpurea & 10,0 & 33,3 & 84,1 & 42,5 & B. ruziziensis & 25,0 & 16,67 & 70,0 & 37,2 \\
\hline A. hybridus & 10,0 & 33,3 & 0,0 & 14,4 & A. hybridus & 25,0 & 33,33 & 13,33 & 23,9 \\
\hline \multicolumn{4}{|c|}{ Milho $45 \mathrm{~cm}-1$ ano } & & \multicolumn{5}{|c|}{ Milho $45 \mathrm{~cm}-3$ anos } \\
\hline \multirow[t]{5}{*}{ B. pilosa } & 100,0 & 100,0 & 100,0 & 100,0 & B. pilosa & 45,4 & 18,1 & 14,8 & 26,1 \\
\hline & & & & & 1. purpurea & 9,1 & 9,1 & 46,3 & 21,5 \\
\hline & & & & & A. hybridus & 13,6 & 27,2 & 14,8 & 18,5 \\
\hline & & & & & R. brasiliensis & 9,1 & 9,1 & 12,9 & 10,34 \\
\hline & & & & & Outras & 22,7 & 36,3 & 11,1 & 23,4 \\
\hline \multicolumn{5}{|c|}{ Consórcio Milho + Brachiaria - 1 ano } & \multicolumn{5}{|c|}{ Consórcio Milho + Brachiaria - 3 anos } \\
\hline B. pilosa & 93,7 & 50,0 & 99,0 & 81,2 & A. hybridus & 75,0 & 66,6 & 40,0 & 60,5 \\
\hline A. hybridus & 6,2 & 50,0 & 1,0 & 18,7 & L. nepetifolia & 25,0 & 33,3 & 60,0 & 39,4 \\
\hline \multicolumn{5}{|c|}{ Brachiaria solteira - 1 ano } & \multicolumn{5}{|c|}{ Brachiaria solteira -3 anos } \\
\hline B. pilosa & 87,5 & 50,0 & 99,0 & 79,2 & A. hybridus & 92,3 & 75,0 & 71,4 & 79,5 \\
\hline A. hybridus & 12,5 & 50,0 & 1,0 & 20,8 & B. ruziziensis & 7,7 & 25,0 & 28,5 & 20,4 \\
\hline \multicolumn{5}{|c|}{ Feijão caupi - 1 ano } & \multicolumn{5}{|c|}{ Feijão caupi - 3 anos } \\
\hline A. hybridus & 83,3 & 50,0 & 99,0 & 77,4 & A. hybridus & 22,5 & 21,4 & 42,4 & 28,8 \\
\hline R. brasiliensis & 8,3 & 25,0 & 0,5 & 11,3 & E. heterophylla & 16,1 & 21,4 & 26,9 & 21,5 \\
\hline \multirow[t]{3}{*}{ C. juncea } & 8,3 & 25,0 & 0,5 & 11,3 & L. nepetifolia & 32,2 & 14,3 & 16,5 & 21,0 \\
\hline & & & & & I. purpurea & 6,4 & 7,1 & 11,3 & 8,3 \\
\hline & & & & & Outras & 22,6 & 35,7 & 2,8 & 20,4 \\
\hline
\end{tabular}

NOTA: Valores da tabela em porcentagem. $\mathrm{DE}$ = densidade relativa; $\mathrm{FR}$ = frequência relativa; $\mathrm{DO}$ = dominância relativa; $\mathrm{VI}=$ valor de importância relativa de espécies daninhas

(Barbour et al., 1998). Em termos percentuais a relação entre a frequência e a área onde a espécie está presente não é direta, mas as proporções de frequências entre as espécies são preservadas. Assim, A. hybridus se destaca das demais por apresentar acima de $50 \%$ de frequência relativa no terceiro ano, nas áreas de consórcio e de braquiária solteira (Tabela 1).

A dominância reflete a capacidade de crescimento da espécie em termos de acúmulo de massa seca, e como ela se distribui no dossel da área na ocupação do espaço e supressão do crescimento das demais espécies (Barbour et al., 1998). No milho solteiro semeado a $90 \mathrm{~cm}$ entre linhas, a Ipomoea purpurea foi a espécie com maior habilidade de crescimento e ocupação do espaço, representando $84 \%$ da massa seca total das plantas na área. Após três anos, no entanto, a espécie foi substituída por outras (Tabela 1). O milho solteiro a $45 \mathrm{~cm}$ entre linhas apresentou somente picão-preto no primeiro ano, já após três anos a corda-de-viola dominou $46 \%$ do espaço disponível. O consórcio milho-braquiária apresentou somente duas espécies daninhas em ambas as áreas (um e três anos de cultivo), sendo que no primeiro ano o picão-preto representou $99 \%$ da dominância, enquanto após três anos as duas espécies dividiram quase equitativamente a área disponível (Tabela 1). No feijão-caupi, $A$. hybridus foi a espécie dominante em ambas áreas (um e três anos de sucessão).

O Valor de Importância (V.I.) de infestação para as espécies constatadas na área indicou que, para milho solteiro a $90 \mathrm{~cm}$ entre linhas, no primeiro ano de implantação o picão-preto e a corda-de-viola representaram cerca de $85 \%$ da infestação; após três anos de cultivo, a ocorrência de espécies na mesma área foi mais equitativa (Tabela 1). $O$ milho solteiro a $45 \mathrm{~cm}$ entre linhas, que na área de um ano praticamente não apresentou infestação, na área após três anos de cultivo apresentou diversas espécies daninhas, com máximo V.I. de $26 \%$ para a espécie de maior ocorrência (Tabela 1). Na área de consórcio, destaca-se o desaparecimento do picão-preto após três anos, e o aumento da ocorrência de caruru roxo neste sistema de cultivo. Para feijão-caupi, no primeiro ano ocorreram somente três espécies daninhas, sendo o caruru responsável por $77 \%$ da importância de infestação; no terceiro ano o número de espécies foi maior e, embora o caruru tenha continuado como a planta daninha mais importante no sistema, sua importância foi reduzida para $28 \%$ (Tabela 1 ).

Os coeficientes de diversidade (Tabela 2) são uma estatística dirigida à compreensão da variedade de indivíduos em uma comunidade vegetal, permitindo inferências sobre as populações em termos de número de espécies e balanço da ocorrência de seus indivíduos (Barbour et al. 1998). O coeficiente de diversidade de Simpson (D) considera mais a abundância das espécies na amostra, sendo menos sensível à riqueza e menos influenciado pela ocorrência das espécies raras (Simpson, 1949; Giavelli et al., 1986). O coeficiente de Shannon-Weiner, por outro lado, considera menos a abundância de indivíduos de cada espécie, sendo mais influenciado pela ocorrência de espécies raras (Barbour et al., 1998).

Os coeficientes de diversidade foram maiores na área com três anos da mesma sucessão comparado ao respectivo tratamento de primeiro ano, exceto para a braquiária solteira (Tabela 2) onde no terceiro ano a densidade de espécies foi de $92 \%$ para o A. hybridus (Tabela 1), o que ocasionou menor diversidade para este tratamento com três anos de manejo (Tabela 2). Os tratamentos foram separados genericamente

Tabela 2. Coeficientes de diversidade de Simpson (D) e Shannon-Weiner (H') em função de períodos de utilização de distintos cultivos de inverno. Embrapa Agropecuária Oeste, Dourados-MS, 2012

\begin{tabular}{ccccc}
\hline \multirow{2}{*}{ Tratamentos } & \multicolumn{2}{c}{ D } & \multicolumn{2}{c}{ H' $^{\prime}$} \\
\cline { 2 - 5 } & 1 ano & 3 anos & 1 ano & 3 anos \\
\hline Milho 90cm & 0,34 & 0,62 & 0,64 & 1,04 \\
Milho 45cm & 0,0 & 0,74 & 0,0 & 1,64 \\
Milho + Brach & 0,12 & 0,38 & 0,23 & 0,56 \\
Brachiaria & 0,22 & 0,14 & 0,38 & 0,27 \\
Feijão caupi & 0,29 & 0,80 & 0,57 & 1,80 \\
\hline
\end{tabular}


em dois grupos, sendo o primeiro composto por todos os tratamentos com ausência de braquiária, com maior diversidade, e o segundo pelos tratamentos de braquiária solteira e do consórcio milho + braquiária, com menor diversidade (Tabela 2). Não há relação direta entre o coeficiente de diversidade (Tabela 2) e o nível de infestação das áreas (Figura 1), pois o comportamento deste parâmetro é complexo e influenciado por diversos fatores. Portanto, estes coeficientes devem ser utilizados de forma complementar a outras informações como a avaliação fitossociológica (Tabela 1).

Sob alta infestação de plantas daninhas, a importância de cada espécie como um componente da competição é reduzida; logo, se os potenciais competitivos forem similares haverá equivalência na ocorrência das espécies resultando usualmente em maior diversidade. Nesta situação, restrições impostas pelo ambiente serão maiores determinantes do desenvolvimento de uma espécie do que o próprio potencial genético (Pitelli \& Pitelli, 2008). Por outro lado, sob infestação moderada o tipo de planta daninha determinará a dificuldade de controle (Pereira et al., 2000).

A análise de agrupamento por similaridade, com base nas distâncias calculadas pelo coeficiente de Jaccard e estruturado pelo método UPGMA (Figura 2), indicou cinco grupos quanto à semelhança de ocorrência de plantas daninhas. O primeiro grupo, com $63 \%$ de similaridade, incluiu o milho solteiro a $90 \mathrm{~cm}$ entre linhas, a braquiária solteira e o consórcio milho + braquiária, todos de primeiro ano; o segundo grupo, com $52 \%$ de similaridade, incluiu os mesmos tratamentos, mas com três anos de implantação; o terceiro grupo, também com $52 \%$ de similaridade, incluiu os tratamentos de milho solteiro a $45 \mathrm{~cm}$ entre linhas e feijão-caupi, ambos com três anos de implantação. Milho a $45 \mathrm{~cm}$ entre linhas no $1^{\circ}$ ano e feijão-caupi $1^{\circ}$ ano, isoladamente, representaram os outros dois grupos (Figura 2). A eficiência do agrupamento foi verificada pelo coeficiente de correlação cofenética, com $95 \%$ de precisão.

O nível de infestação por plantas daninhas na lavoura da safra de verão depende do cultivo implantado na área durante o período de outono-inverno; cultivos de segunda safra que proporcionem menor cobertura do solo, ou cuja massa seca possua baixa relação $\mathrm{C}: \mathrm{N}$, resultam em maiores níveis de infestação na safra subsequente; somente um ano de manejo diferenciado não é suficiente para atenuar a ocorrência de espécies daninhas mais problemáticas, cujos resultados

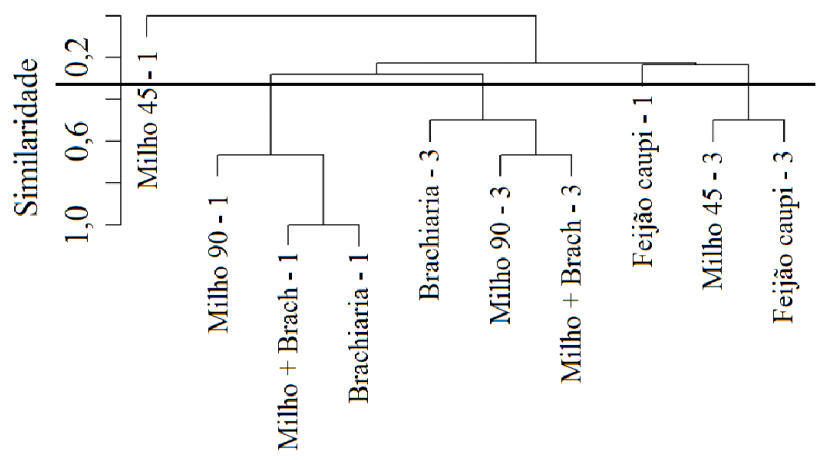

Figura 2. Análise de agrupamento por similaridade pelo método UPGMA com base nos coeficientes binários de Jaccard, em função de períodos de utilização de distintos cultivos de inverno. Coeficiente de correlação cofenética = 0,95. Embrapa Agropecuária Oeste, Dourados-MS, 2012 positivos são observados a partir do terceiro ano de manejo; a composição de espécies infestantes muda de acordo com o cultivo de outono-inverno, e cada cultivo selecionou determinadas espécies daninhas; assim, a simples sucessão de cultivos repetida na mesma área anualmente não é suficiente para manter todas as espécies daninhas em nível igualitário, e a rotação de culturas ao longo do tempo se faz necessária.

A braquiária, tanto solteira como no consórcio, foi a grande responsável por eliminar parte significativa da ocorrência de plantas daninhas, o que refletiu diretamente nos coeficientes de diversidade obtidos. Esta contribuição torna-se importante na determinação da cultura mais adequada para entrar no sistema de sucessão com a cultura da soja na safra de verão.

\section{Conclusões}

Após três anos de cultivo, em termos gerais, os tratamentos apresentaram aumento no índice de infestação em relação ao primeiro ano.

No primeiro ano, a planta daninha mais importante foi Bidens pilosa, que após três anos foi parcialmente substituída por outras espécies como Leonotis nepetifolia e Euphorbia heterophylla.

Os maiores coeficientes de diversidade estiveram associados a maiores níveis de infestação, pois as novas espécies observadas se somaram às presentes. Amaranthus hybridus foi a espécie mais persistente, estando presente em ambos os anos independentemente do cultivo de inverno.

A braquiária implantada no outono-inverno contribuiu significativamente para menor infestação de plantas daninhas no cultivo de soja subsequente, e os cultivos de milho solteiro a $90 \mathrm{~cm}$ entre linhas e feijão caupi proporcionaram aumento no nível de infestação ao longo do tempo.

\section{Literatura Citada}

Aldrich, R. J. Weed-crop ecology. Belmont: Wadsworth, 1984. $465 \mathrm{p}$.

Austin, M. P.; Greig-Smith, P. The application of quantitative methods to vegetation survey. Journal of Ecology, v.56, n.3, p.827-844, 1968. <http://www.jstor.org/stable/2258109>. 14 Dez. 2013.

Barbour, M. G.; Burk, J. H.; Pitts, W. D. Terrestrial plant ecology. Menlo Park: Benjamin/Cummings, 1998. 688p.

Ceccon, G.; Staut, L. A.; Sagrilo, E.; Machado, L. A. Z.; Nunes, D. P.; Alves, V. B. Legumes and forage species sole or intercropped with corn in soybean-corn succession in Midwestern Brazil. Revista Brasileira de Ciência do Solo, v.37, n.1,p.204-212, 2013. $<$ http://dx.doi.org/10.1590/S0100-06832013000100021>.

Giavelli, G.; Rossi, O.; Sartore, F. Comparative evaluation of four species diversity indices related to two specific ecological situations. Field Studies, v.6, n.3, p.429-438, 1986. <http://fsj.field-studies-council.org/media/342791/ vol6.3_176.pdf>. 12 Dez. 2013

Gomes, G. L. G. C.; Ibrahim, F. N.; Macedo, G. L.; Nobrega, L. P.; Alves, E. Cadastramento fitossociológico de plantas daninhas na bananicultura. Planta Daninha, v.28, n.1, p.61-68, 2010. <http://dx.doi.org/10.1590/S0100$83582010000100008>$. 
Lazzarotto, C. Época de semeadura e riscos climáticos para o milho na safra outono-inverno, no sul de Mato Grosso do Sul. Dourados: Embrapa Agropecuária Oeste, 2002. (Comunicado Técnico 70). <http://ainfo.cnptia.embrapa.br/digital/bitstream/ item/24728/1/COT200270.pdf $>$. 26 Nov. 2013.

Mainardi, J. T. Reação de espécies vegetais a Pratylenchus brachyurus. Aquidauana: Universidade Estadual de Mato Grosso do Sul, 2013, 47p. Dissertação Mestrado. <http:// www.uems.br/pgagro/arquivos/8_2013-07-18_16-20-58. pdf>. 26 Nov. 2013.

Pereira, E. S.; Velini, E. D.; Carvalho, L. R. de; Maimoni-Rodella, R. C. S. Avaliações qualitativas e quantitativas de plantas daninhas na cultura da soja submetida aos sistemas de plantio direto e convencional. Planta Daninha, v.18, n.2, p.207-216, 2000. $<$ http://dx.doi.org/10.1590/S0100-83582000000200003>.

Pitelli, R. A.; Pitelli, R. L. C. M. Biologia e ecofisiologia das plantas daninhas. In: Vargas, L.; Roman, E. S. (Orgs.). Manual de manejo e controle de plantas daninhas. Passo Fundo: Embrapa Trigo, 2008. p.11-38.

$\mathrm{R}$ Core Team. $R$ : a language and environment for statistical computing. Viena: R Foundation for Statistical Computing, 2013. <http://www.R-project.org>. 01 Out. 2013.
Silva, A. A. da; Ferreira, F. A.; Ferreira, L. R.; Santos, J. B. dos; Biologia de plantas daninhas. In: Silva, A.A.; Silva, J.F. (Orgs.) Tópicos em manejo de plantas daninhas. Viçosa - MG: UFV, 2007. p.17-61.

Silva, F. M. L.; Abreu, M. L.; Brachtvogel, E. L.; Curcelli, F.; Gimenes, M. J.; Lara, A. C. C. Moléculas de herbicidas seletivos à cultura da mandioca. Revista Trópica, v.3, n.2, p.61-72, 2009. <http://www.ccaa.ufma.br/revistatropica/ ArtigosV3N2/Moleculas\%20_\%20herbicidas_\%20\%20 Fitot.pdf $>.26$ Nov. 2013.

Simpson, E. H. Measurement of diversity. Nature, v.163, n.4148, p.688, 1949. <http://dx.doi.org/10.1038/163688a0>.

Sneath, P. H.; Sokal, R. R. Numerical taxonomy: The principles and practice of numerical classification. San Francisco: W.H. Freeman, 1973. 573p.

Souza, L. S.; Velini, E. D.; Martins, D.; Rosolem, C. A. Efeito alelopático de capim-braquiária (Brachiaria decumbens) sobre o crescimento inicial de sete espécies de plantas cultivadas. Planta Daninha, v.24, n.4, p.657-668, 2006. <http://dx.doi.org/10.1590/S0100$83582006000400006>$. 